\title{
Dynamical Magnetic Response of Iron Oxide Nanoparticles inside Live Cells
}

David Cabrera, ${ }^{\dagger \neq}$ Annelies Coene, ${ }^{\forall}$ Jonathan Leliaert, ${ }^{\nabla}$ Emilio J. Artés-Ibáñez, ${ }^{\dagger}$ Luc

$$
\text { Dupré, }{ }^{\forall} \text { Neil D. Telling, },^{* *} \text { and Francisco J. Teran, }, \aleph^{* * *}
$$

$\dagger$ - iMdea Nanociencia, Campus Universitario de Cantoblanco, C\Faraday, 9, 28049 Madrid, Spain

†- Institute for Science \& Technology in Medicine, Keele University, Guy Hilton Research

Centre. Thornburrow Drive, Hartshill, Stoke-on-Trent ST4 7QB, United Kingdom.

$\forall$ - Department of Electrical Energy, Metals, Mechanical Constructions and Systems, Ghent University, Technologiepark 913, 9052 Zwijnaarde, Belgium.

$\nabla$ - Department of Solid State Sciences, Ghent University, Krijgslaan 281/S1, 9000 Ghent, Belgium.

ふ-Nanobiotecnología (iMdea-Nanociencia), Unidad Asociada al Centro Nacional de

$$
\begin{gathered}
\text { Biotecnología (CSIC), } 28049 \text { Madrid, Spain. } \\
\text { *n.d.telling@keele.ac.uk **francisco.teran@imdea.org }
\end{gathered}
$$

KEYWORDS. magnetic nanoparticles, dynamical magnetic response, magnetic interactions, magnetic hyperthermia, live cells. 


\section{ABSTRACT.}

Magnetic nanoparticles exposed to alternating magnetic fields have shown a great potential acting as magnetic hyperthermia mediators for cancer treatment. However, a dramatic and unexplained reduction of the nanoparticle magnetic heating efficiency has been evidenced when nanoparticles are located inside cells or tissues. Recent studies suggest the enhancement of nanoparticle clustering and/or immobilization after interaction with cells as possible causes, although a quantitative description of the influence of biological matrices on the magnetic response of magnetic nanoparticles under AC magnetic fields is lacking. Here, we studied the effect of cell internalization on the dynamical magnetic response of iron oxide nanoparticles (IONPs). AC magnetometry and magnetic susceptibility measurements of two magnetic core sizes $(11$ and $21 \mathrm{~nm})$ underscored differences in the dynamical magnetic response following cell uptake with effects more pronounced for larger sizes. Two methodologies have been employed for experimentally determining the magnetic heat losses of magnetic nanoparticles inside live cells without risking their viability, as well as the suitability of magnetic nanostructures for in vitro hyperthermia studies. Our experimental results -supported by theoretical calculations- reveal that the enhancement of intracellular IONP clustering mainly drives the cell internalization effects rather than intracellular IONP immobilization. Understanding the effects related to the nanoparticle transit into live cells on their magnetic response will allow to design of nanostructures containing magnetic nanoparticles whose dynamical magnetic response will remain invariable in any biological environments, allowing sustained and predictable in vivo heating efficiency. 
In the last twenty years, magnetic nanoparticles (MNPs) have witnessed an increasing interest in biomedical applications thanks to their potential for acting as drug delivery ${ }^{1}$ or gene transfection ${ }^{2}$ nanocarriers, magnetic separators, ${ }^{3}$ sensing transducers, ${ }^{4}$ imaging tracers $^{5-6}$ or hyperthermia mediators. ${ }^{7-8}$ Among MNPs, iron oxide nanoparticles (IONPs) are probably the most investigated thanks to the precise control of synthesis with tailored structural, colloidal, and magnetic properties ${ }^{9-12}$ and the negligible toxicity drawbacks. ${ }^{13}$ Interestingly, IONPs show efficient and minimally invasive capabilities to act as local heating mediators for destroying tumor tissues when subjected to alternating magnetic fields $\left(H_{A C}\right)$, a technique known as magnetic hyperthermia. ${ }^{14}$ Under such circumstances the magnetic response is characterized by non-reversible magnetization processes, resulting in heat losses that locally increase the temperature of IONP surroundings. In addition, IONPs with suitable hyperthermia performance have also shown great capabilities as imaging tracers for the emerging technique of magnetic particle imaging (MPI). ${ }^{5,15}$ This technique combines high quality imaging with the quantitative ability to meet or exceed the sensitivity, spatial and temporal resolution of established clinical techniques such as positron emission tomography, magnetic resonance imaging and computed tomography. As the MPI signal strength and phase originating from IONPs -related to the magnetic heat losses- is very different to the signal from the tissues, the background signal can be easily separated. Consequently, MPI displays excellent contrast and the signal is hardly attenuated by tissue owing to the use of low-frequency $(\sim 25 \mathrm{kHz}) H_{A C}$. The application of an AC magnetic field to IONPs induces a time-varying signal required for MPI with similar dynamical magnetic features than the characteristic ones related to magnetic hyperthermia. Thus, the potential of gathering heating (magnetic hyperthermia) and high-resolution 
imaging (MPI) capabilities at the same IONP has boosted the research on material sciences for supplying high quality magnetic colloids with outstanding magnetic properties under $H_{A C}{ }^{9,11-12,16}$ for theragnosis issues.

Despite the huge potential of IONPs for exploiting their magnetic properties in biomedical applications, recent studies have evidenced that their dynamical magnetic response is dramatically altered into biological environments. ${ }^{15}, 17-20$ The enhancement of IONP clustering, ${ }^{21-23}$ and/or the influence of the viscosity $(\eta)$ of their surrounding media ${ }^{24-}$ ${ }^{25}$ either inside cells, or within the extracellular environment, leads to substantial variations of the magnetic behavior under $H_{A C}{ }^{15,17,26-27}$ Also, cellular uptake leads to further modifications of the magnetic response of MNP related to intracellular biodegradation processes on a long term ( $>24$ hours). ${ }^{20}$ Concerning the magnetic heat release of MNPs in cellular environments, several studies reported a significant reduction between 70 and $90 \%$, depending on nanoparticle size, chemical composition, and/or aggregation structure. ${ }^{17,27}$ Authors correlated such magnetic heating reduction with the inhibition of Brownian relaxation processes (i.e. MNP immobilization) and/or particle-particle magnetic dipolar interactions, occurring either inside the intracellular compartments or at the cell membrane. However, these experimental results did not quantify the effect on reducing the magnetic heat losses associated with MNP immobilization or interacting phenomena. In addition, the results were mainly obtained in fixed cells (i.e. cells with a generalized protein crosslinking), which could additionally contribute to the variation of the dynamical magnetic response with respect to live cells. Beside, Soukup et al. ${ }^{18}$ reported on how magnetization relaxation processes, probed by AC magnetic susceptibility (ACS) measurements, varied when IONPs are located in live cells, with respect to colloidal dispersion. Two IONP sizes 
characterized by different predominant relaxation mechanisms were studied, revealing experimental evidences consistent with measurements of immobilized nanoparticle suspensions. Similar results were obtained by Moise et al. ${ }^{19}$ when the magnetic anisotropy constant of IONPs was directly varied by doping either with zinc or cobalt, the latter case yielding high-anisotropy particles that were blocked at all frequencies employed. Although ACS measurements provide extremely useful insights into the dynamic response of MNPs in biological environments, the typical field intensity values employed in these measurements $(<0.04 \mathrm{kA} / \mathrm{m})$ are far from those used in magnetic hyperthermia ${ }^{8}$ or MPI. ${ }^{28-}$ ${ }^{29}$ It is therefore difficult to extract general conclusions from ACS measurements alone, since relaxation times and magnetization reversals are strongly modulated by the external field intensity. ${ }^{30}$

The magnetic response of MNPs under $H_{A C}$ is generally probed by determining the specific absorption rate (SAR), which represents the heat loss per second per gram of magnetic material. SAR is mainly measured using calorimetric methods allowing the quantification of MNP heat dissipation losses by considering different extrinsic and intrinsic MNP parameters. ${ }^{9}, 11,31-32$ However, calorimetry measurements ${ }^{33}$ are inaccurate and difficult to standardize. ${ }^{34-35}$ At the same time, the calorimetry method requires parameters, such as specific heat, which are difficult to be precisely determined in biological matrices (i.e. cells, or tissues) without affecting their integrity. In contrast, AC magnetometry $(\mathrm{ACM})^{36}$ affords a direct and accurate method to probe and quantify the magnetic losses of MNP by measuring their hysteresis loops under $H_{A C}$ conditions and considering that $\mathrm{SAR}=\mathrm{A} \cdot f,{ }^{37}$ where $\mathrm{A}$ is the area enclosed by the hysteresis loop and $f$ is the field frequency. Interestingly, ACM needs shorter measurement times (generally, less 
than sixty seconds) than calorimetric ones (typically few tens of minutes), reducing considerably the exposure of the biological matrices to the thermal stress mediated by MNPs under $H_{A C}$ conditions. Also, the measurement acquisition process does not require the use of probes (such as thermometers) which need to be in contact with the biological sample, strongly reducing biological risks for the user or the sample. Moreover, AC hysteresis loops provide experimental data more suitable to be modeled than the calorimetric ones. Micromagnetic models are widely employ to numerically simulate $\mathrm{ACM},{ }^{30,36,32,38}$ turning into a powerful method for studying the dynamical magnetic response of MNPs in biological entities. Nevertheless, how the MNP internalization into cells influences their AC hysteresis loops and in consequence, their magnetic heat losses, remains an open question whose answer will benefit the in vivo magnetic hyperthermia studies.

In this work, we report on a magnetic study of IONPs internalized in live cells performed by ACM and ACS measurements. We assess the influence of the cell internalization on the dynamical magnetic response of two commercial citric acid coated IONPs of different core sizes $(11 \mathrm{~nm}$ and $21 \mathrm{~nm})$. This IONP set is characterized for the prevalence of distinct magnetic relaxation mechanisms (Néel for $11 \mathrm{~nm}$ IONP size and Brownian for $21 \mathrm{~nm}$ size). We assess the AC magnetic susceptibility (up to $500 \mathrm{kHz}$ ) and $\mathrm{AC}$ hysteresis loops (100 $\mathrm{kHz}, \pm 20 \mathrm{kA} / \mathrm{m}$ ) of the same samples: similar mass and volume of IONPs dispersed in aqueous solutions or inside live cells. In order to better understand the behavior of the IONPs in live cells, we also studied the dynamical magnetic response of IONPs when varying environmental viscosity and nanoparticle aggregation. In addition, numerical 
simulations of the ACS and ACM results provide a qualitative and quantitative description of the trends found in the experimental observations. Understanding the underlying reasons behind the changes of dynamical magnetic behaviour of MNPs into biological matrices is of great importance to design nanostructures whose magnetic heating efficiency and/or MPI signal remains unaffected in any biological environments.

\section{RESULTS AND DISCUSSION}

\section{Dynamical magnetic response of IONPs in live cells}

We performed ACS and ACM studies of IONPs dispersed either in double distillated water $\left(\mathrm{ddH}_{2} \mathrm{O}\right)$ at $1 \mathrm{~g}_{\mathrm{Fe}} / \mathrm{L}$, or inside live cells to determine the prevailing magnetic relaxation mechanism, and the related magnetic heat losses. Figure 1 shows the dynamic magnetic measurements of $11 \mathrm{~nm} \pm 4 \mathrm{~nm}$ and $21 \pm 6 \mathrm{~nm}$ core IONPs dispersed in water (solid lines) at $\rho_{\mathrm{Fe}}=1 \mathrm{~g}_{\mathrm{Fe}} / \mathrm{L}$. The ACS measurements of the smaller nanoparticles $(11 \mathrm{~nm})$, dispersed in $\mathrm{ddH}_{2} \mathrm{O}$ (Figure 1a, solid black lines), show a constant value of the real ACS component ( $\chi$ ') from $10 \mathrm{~Hz}$ up to $\sim 2 \mathrm{kHz}$, and then a progressive decrease towards larger frequencies. Since the real ACS component $\left(\chi^{\prime}\right)$ dominates within the measured frequencies, a Néel peak is predicted at higher frequencies above the measurable range (i.e. $>>500 \mathrm{kHz}$ ), whilst the imaginary component ( $\chi$ ') shows a broad and less pronounced shoulder around $9 \mathrm{kHz}$. These features are representative of the coexistence of Brownian and Néel relaxation processes in these IONPs dispersed in water. ${ }^{39-40}$ Indeed, the less pronounced $\chi$ '" peak observed at $f=9 \mathrm{kHz}$ is related to the Brownian relaxation process as confirmed later in the viscosity study (see Figure 3). Such coexistence of relaxation processes for the $11 \mathrm{~nm}$ IONPs could be assigned to the large size distribution of the cores, which is asymmetric towards large sizes (see Figure S1 a,c). Typically, IONPs of large sizes have sufficient 
anisotropy energy to be magnetically blocked around the $f=9 \mathrm{kHz}$ region, allowing the observation of a Brownian contribution. The prevalence of the Néel relaxation mechanism indicates that the majority of the IONPs have Néel relaxation times shorter than the AC field cycle time within the frequency range studied. Beside, ACS measurements of the $21 \mathrm{~nm}$ IONPs dispersed in $\mathrm{ddH}_{2} \mathrm{O}$ (Figure $1 \mathrm{~b}$-solid black curve) show an entirely different scenario. On the one hand, the $\chi^{\prime}$ component is constant from $10 \mathrm{~Hz}$ up to $1 \mathrm{kHz}$ followed by a progressive decrease at larger frequencies. On the other hand, $\chi$ "' shows a well pronounced (Brownian related) peak at $9 \mathrm{kHz}$ and a much weaker high-frequency (Néel related) component, revealing the prevalence of Brownian relaxation in the studied frequency range for the larger $(21 \mathrm{~nm})$ IONPs. This is consistent with a large proportion of IONPs whose internal magnetic moment remains aligned to the $\mathrm{AC}$ field during the $\mathrm{AC}$ field cycle, and indicates that these particles have higher anisotropy energy barrier than the $11 \mathrm{~nm}$ IONPs.

ACM measurements were performed under $H_{A C}$ conditions close to those currently employed in magnetic hyperthermia treatments ${ }^{8}$ and therefore, with magnetic field intensities few orders of magnitude greater than those employed for ACS measurements. Figures $1 \mathrm{c}, \mathrm{d}$ (solid black lines) show distinct hysteretic behavior of both sizes of IONPs dispersed in $\mathrm{ddH}_{2} \mathrm{O}$. While the values of magnetization at the maximum field intensity $\left(\mathrm{M}_{\mathrm{MAX}}\right)$ or remanence $\left(\mathrm{M}_{\mathrm{R}}\right)$ are larger for the $11 \mathrm{~nm}$ IONP than for $21 \mathrm{~nm}$, the area is evidently larger for the $21 \mathrm{~nm}$ IONPs due to larger magnetic coercivity $\left(\mathrm{H}_{\mathrm{C}}\right)$ values. Assuming that the hysteresis area is proportional to the magnetic heating losses, we can extract SAR for $11 \mathrm{~nm}$ and $21 \mathrm{~nm}$ IONPs dispersed in water solutions, whose values are 40 \pm 2 and $76 \pm 4 \mathrm{~W} / \mathrm{g}$, respectively. These different SAR values depending on particle size 
can be understood in terms of IONP volume $(V),{ }^{9}$ or in other words: different magnetic anisotropy energy barrier $K V$, where $K$ is the magnetic anisotropy. ${ }^{38}$

In order to assess the dynamical magnetic response in live cells, we incubated IONPs with a breast cancer cell line (MCF-7), following a standard cell culture protocol ${ }^{41}$ (see Materials and Methods section). After 24 hours of incubation, cell culture medium with nanoparticles was extracted, the IONPs loaded cells were rinsed five times with PBS to remove all non-internalized IONPs and detached from the cell culture flask. Immediately after, we performed ACS and ACM measurements on the live cell suspensions and reseeded part of the cells utilized in the magnetic measurements to check the presence of IONPs inside cells by microscope techniques as described later.

Dynamical magnetic response of IONPs inside cells in comparison with the ones performed in water dispersions reflects strong differences. In ACS (Figure 1ab - solid green lines), the absolute values of $\chi$ ' dramatically drop for both IONPs sizes after cell internalization across the entire frequency range but at a different extent, being more pronounced for $21 \mathrm{~nm}$ IONPs. In contrast, $\chi$ " shows a flat signal with values near zero across the overall measured frequency range independently of IONP size.

In addition, ACM curves of IONPs (Figure $1 \mathrm{c}, \mathrm{d}$ ) internalized in cells significantly vary their sigmoidal shape and/or the opening (lowering coercivity and remanence) in comparison to the curves of IONPs obtained in water dispersion. Note that the variation of the loop areas for IONP dispersed in water compared to the ones inside cells is more pronounced for the larger nanoparticles size. This is clearly reflected in the magnetic SAR values obtained from the $\mathrm{AC}$ hysteresis loops, which change from $40 \pm 2 \mathrm{~W} / \mathrm{g}$ in $\mathrm{ddH}_{2} \mathrm{O}$ to $36 \pm 1 \mathrm{~W} / \mathrm{g}$ in cells for $11 \mathrm{~nm}$ IONPs (i.e. $10 \%$ reduction), and from $76 \pm 4 \mathrm{~W} / \mathrm{g}$ in $\mathrm{ddH}_{2} \mathrm{O}$ to 
$38 \pm 1 \mathrm{~W} / \mathrm{g}$ in cells for $21 \mathrm{~nm}$ IONPs (49\% reduction). Thus, the larger nanoparticles show a more substantial reduction of the magnetic heat losses, while the smaller size almost maintain the SAR values. It is worth noting the preservation of heat losses of both IONPs into the cellular environment under $H_{A C}$. Recent works report on experiments with cells cultures where negligible macroscopic temperature rises were observed. ${ }^{42-44}$ This limited temperature enhancement raises fundamental questions as to whether MNPs should be discounted as an efficient source of thermal stress in live cells, despite the observation of a significant reduction of cell viability. Different apoptotic inductive phenomena, such as lysosome and or/cell membrane permeabilization or mechanical stimulation have been suggested as alternative mechanisms for cell death instead of thermal stress. ${ }^{45}$ By measuring the AC magnetization loops of IONPs under magnetic hyperthermia field conditions, our results reveal the existence of IONP magnetic losses and consequently, heat dissipation inside the cells. Hence, the observation of no temperature changes in cell cultures could be related to their specific experimental conditions in these previous studies rather than to the removal of the intrinsic magnetic heating losses of IONPs inside cells ${ }^{42}$. For example, a very low IONP concentration in the overall cell media volume, or strong thermal losses of the experimental set-up may hinder the observation of a significant temperature rise.

In order to monitor the IONP internalization and conditions of the cells after the magnetic measurements, we reseeded one fifth of the cells employed in the magnetic measurements, recovering adherence after 12 hours. Immediately after, the cells were subjected to fixation, preparation and/or dyeing procedures, and visualized under suitable microscopy techniques (See Materials and Methods section). Figure 2 shows a representative set of the reseeded 
cell images. In Prussian Blue images, one can observe characteristic perinuclear demilune halos around the cell nucleus in both IONP sizes incubated cultures (Figure $2 \mathrm{a}, \mathrm{d}$ ), pointing to an intra-cytoplasmic internalization of nanoparticles and discounting appreciable IONP sedimentation around or onto cells. Quantitatively assessed by ICP-MS on the nonreseeded cells fraction, both incubated cultures yielded comparable values of IONP internalization for each nanoparticle size: $28 \mathrm{pg}_{\mathrm{Fe}} /$ cell for $11 \mathrm{~nm}$ IONPs and $21 \mathrm{pg}_{\mathrm{Fe}} / \mathrm{cell}$ for $21 \mathrm{~nm}$ IONPs (See Materials and Methods section for iron quantification method).

In cell TEM images (Figure 2b, e), IONPs are mostly found in intra-cellular vesicles, confirming that the measured ACS and ACM signal do not arise from IONPs located outside of cells. In particular, images evidence massive aggregation of IONPs into intracellular vesicles, as reported elsewhere. ${ }^{17}$ The typical sizes of subcellular vesicles (several hundreds of nanometers) where IONPs are located reflect the clustering effects when IONPs transit across the cytoplasm. Such cluster sizes represent a huge increase in the degree of aggregation with respect to the IONP clusters formed in water, which have hydrodynamic sizes $\left(\mathrm{D}_{H}\right.$ measured as z-average) of $50 \mathrm{~nm}$ and $67 \mathrm{~nm}$ for $11 \mathrm{~nm}$ and $21 \mathrm{~nm}$ IONPs, respectively (Fig. S1 f, g).

Finally, we evaluated the cell morphology by using 4',6-diamidino-2-phenylindole (DAPI) and ActinRed ${ }^{\circ}$ dyeing for visualization under confocal microscopy (Figure $2 \mathrm{c}, \mathrm{f}$ ); as well as staining-free under bright field microscopy (Figure S2). Images show wellspread cells which are free from morphology aberrations, whilst live/dead staining confirmed cell viability (Fig. S3). In this regard, cells are kept at room temperature $\left(25^{\circ} \mathrm{C}\right)$ for 5 minutes during the $\mathrm{AC}$ hysteresis loops measurements, being only exposed to magnetic hyperthermia field conditions for a short period of time $(<5 \mathrm{~s})$ in order to 
preserve cell viability. After confirming the intracellular location of IONPs during magnetic experiment, we conclude that the above results described the influence of the cellular environment on the dynamical magnetization response of IONPs. This influence is observed in ACM and ACS measurements in both IONP sizes, being more pronounced for the larger size. In order to better understand such effects on the dynamic magnetic response of IONPs, we developed a general methodology aiming to determine the effects of cell internalization on the magnetic heat losses of magnetic nanoparticles. This methodology is based on the assessment of the viscosity and aggregation effects on the ACM and ACS measurements of IONPs dispersed in aqueous solutions.

\section{Influence of viscosity on the dynamical magnetic response of IONPs}

To assess the environmental viscosity effects of the studied IONPs on their dynamical magnetic response, we performed ACM and ACS measurements of IONPs dispersed in aqueous media with an increasing glycerol fraction for raising viscosity $(\eta)$. The highest $\eta$ value of the used viscous dispersions (See Table S1a) is comparable to the one

determined inside intracellular vesicles in recent studies. ${ }^{25,}{ }^{46}$ Figure 3 shows ACM and ACS measurements of $11 \mathrm{~nm}$ and $21 \mathrm{~nm}$ IONPs dispersed in media with different viscosity. AC hysteresis loops of $11 \mathrm{~nm}$ IONPs (Fig. 3a) present no significant variation when increasing medium viscosity. Consequently, the area of the AC hysteresis loops and their related SAR value do not significantly change in the studied viscosity range (Fig. 4a). Indeed, the viscosity dependence of ACS measurements (Figure 3b) also show small changes. In order to discount IONP agglomeration effects ${ }^{32,47}$ induced during the viscous dispersion preparation that may be reflected on the ACS and ACM results, we measured the 
hydrodynamic sizes $\left(D_{H}\right)$ in glycerol dispersions (up to $32 \% \mathrm{v}_{G l} / \mathrm{v}$, where $\mathrm{v}_{G l y}$ is the glycerol volume and $\mathrm{v}$ is the total dispersion volume) by DLS, showing no significant variation of $D_{H}$ (see Figure S1). Thus, we assign the lack of viscosity-dependent dynamical magnetic response of the $11 \mathrm{~nm}$ IONPs to the predominance of the Néel relaxation mechanism in this sample.

Conversely, the dynamical magnetic response of $21 \mathrm{~nm}$ IONPs implies a stronger influence of medium viscosity. Figure 3c shows AC magnetization loops, where the loop of the area (A) reduces up to $37 \%$ of the loop area (A) when viscosity has values comparable to those reported on cell vesicles. ${ }^{25}$ Consequently, heating losses (i.e. SAR values) shrink from $76 \pm 5$ to $48 \pm 3 \mathrm{~W} / \mathrm{g}$ when $\eta$ increases (Fig.4a). Simultaneously, ACS measurements (Fig 3d) show a shift towards lower frequencies for the $\chi$ " peak $(f=9 \mathrm{kHz}$ in water) with increasing medium viscosity. We understand such experimental magnetic behaviour in terms of the prevalence of Brownian relaxation process for the $21 \mathrm{~nm}$ IONPs, in the range of studied viscosity values. Another interesting aspect of these ACS and ACM measurements is their distinct sensitivity to viscosity. Indeed, ACS measurements are more sensitive to medium viscosity than ACM, which can be assigned to the influence of field intensity on the magnetization dynamics: larger field intensities reduce the sensitivity to viscosity. ${ }^{30,38}$ In fact, the field intensity differs by more than two order of magnitude decades in the case of ACS and ACM measurements (i.e. $\mathrm{H}_{\mathrm{MAX}} \sim 0.04 \mathrm{kA} / \mathrm{m}$ and in $20 \mathrm{kA} / \mathrm{m}$, respectively). In this regard, field intensity modulates dynamic magnetic relaxation mechanisms due to the appearance of a magnetic torque, ${ }^{30,38,48}$ leading to the distinct sensitivity of the IONP magnetic response with the environmental viscosity. In any case, it is worth to note that the viscosity trend observed in the ACM and ACS 
measurements is significantly far from the results observed in live cells for both IONP sizes. On one hand, this disagreement can be better observed in the viscosity dependence of the characteristic magnetic parameters of AC hysteresis loops (i.e. $A, M_{R}, H_{C}$ and $M_{M A X}$ ) (Fig. S5) shown in Figure 3 a,c. Here, strong differences arise with respect to results obtained in cells, especially for $21 \mathrm{~nm}$ IONPs and, to a lesser extent, for the $11 \mathrm{~nm}$ IONPs. On the other hand, ACS measurements clearly show significant discrepancies with respect to measurements of IONPs in live cells at the highest media viscosity values. Values of real part of the $\operatorname{ACS}\left(\chi^{\prime}\right)$ measured at the highest medium viscosity are far from those measured inside cells for both IONPs sizes, despite such $\eta$ values are comparable to the ones determined into intracellular environment. ${ }^{24}$ Regarding the imaginary part of the ACS $\left(\chi^{\prime \prime}\right)$, measurements of IONPs at the largest medium viscosity value and inside cells seem to be far from overlapped, especially inside the $\sim 5-50 \mathrm{kHz}$ range. In case of the larger nanoparticles instead, we can clearly observe that the Brownian peak, displaced to $\sim 100 \mathrm{~Hz}$ due to the enhancement of medium viscosity, is far from reaching a flat profile shown for IONPs inside cells. Thus, although the variations of $\eta$ leads to modifications on the dynamical magnetic response of the studied IONPs, viscosity effects do not qualitatively replicate the magnetic trends observed in cells. Hence, we alternatively assessed the effects of increasing aggregation on the dynamical magnetic response of IONPs.

\section{Influence of aggregation on the dynamical magnetic response of IONP}

In order to probe the nanoparticle aggregation effects on the dynamical magnetic response, we carried out $\mathrm{ACM}$ and $\mathrm{ACS}$ measurements on IONP aggregates in aqueous dispersions whose size was intentionally raised up to $400 \mathrm{~nm}$ (see Material and Methods and table S2). The IONP hydrodynamic size $\left(D_{H}\right)$ values of the studied IONP aggregates 
are in the range of the subvesicle sizes where MNPs are located following their transit across the cytoplasm after cell uptake. ${ }^{49}$ Figure 5 shows ACM and ACS measurements performed for aqueous dispersions of $11 \mathrm{~nm}$ and $21 \mathrm{~nm}$ IONPs at different $D_{H}$ sizes. The AC magnetic response is significantly influenced by the IONP aggregation, in agreement with recent observations showing the effects of magnetic dipolar interactions on the $\mathrm{AC}$ hysteresis loops. ${ }^{32}$ Indeed, considering the trend obtained in ACM and especially ACS measurements for both IONPs, a convergence towards the measurements in cells can be found. In this regard, Figures 5ac show that the AC hysteresis loops of $11 \mathrm{~nm}$ and $22 \mathrm{~nm}$ IONPs significantly vary the shape with increasing $D_{H}$ (See also Figure S4), although to a different extent depending on particle size. The changes are again more pronounced for the larger IONP size. The corresponding reduction of SAR values is lower than $10 \%$ for the smaller $(11 \mathrm{~nm})$ IONPs: from $40 \pm 2 \mathrm{~W} / \mathrm{g}$ at $D_{H}=50 \mathrm{~nm}$ to $37 \pm 3 \mathrm{~W} / \mathrm{g}$ at $D_{H}=311 \mathrm{~nm}$. Indeed, magnetic heat losses remain roughly constant for the $11 \mathrm{~nm}$ IONPs in the studied $D_{H}$ size range (Fig. 4b). However, SAR values of larger (21 nm) IONPs significantly shrink $\sim 60 \%$ from $76 \pm 4 \mathrm{~W} / \mathrm{g}$ at $D_{H}=67 \mathrm{~nm}$ to $31 \pm 2 \mathrm{~W} / \mathrm{g}$ at $D_{H}=303 \mathrm{~nm}$ (Figure $4 \mathrm{~b}$ ). This reduction is considerably larger than the one obtained when varying viscosity and comparable to the one observed inside cells.

The underlying reason for the reduction in loop area and consequently SAR lies in a generalized decrease of $M_{R}$ and $H_{C}$ in the magnetization loops, and to a lesser extent of $M_{M A X}$ (See Figure S6) while increasing $D_{H}$. This variation of the AC hysteresis loops produces an attenuation of the sigmoidal shape, unequivocally evidenced when the loops are normalized to $M_{M A X}$ (see Figure S4). Most significantly, all characteristic features of the AC hysteresis loops (i.e. $A, M_{R}, M_{M A X}$, and $H_{C}$ ) achieve values close to those observed in 
live cells at the largest $D_{H}$ values (Figure S6). The increase of intra-aggregate magnetic dipolar interactions while increasing $D_{H}$ can explain such magnetic behavior, as recently

reported. ${ }^{32}$ In addition, ACS measurements significantly change when increasing $D_{H}$. Figure $5 \mathrm{~b}$ shows that for $11 \mathrm{~nm}$ IONPs, the Brownian peak on the ACS imaginary part shifts towards lower frequencies when increasing $D_{H}$, similarly to the case of increasing $\eta$. We understand this behaviour in terms of the variation of the hydrodynamic volume, which modulates Brownian relaxation time in a similar way to $\eta$. However, in contrast to the small changes observed with increasing viscosity, noticeable changes of the ACS real part are observed when increasing $D_{H}$. In particular, the decrease of $\chi^{\prime}$ values resembles the ACS results measured for IONPs inside live cells (Figure 5b-solid green lines). Similar effects are observed for the larger $(21 \mathrm{~nm})$ IONPs, where the ACS imaginary part shows a progressive broadening and shift of the Brownian peak at $9 \mathrm{kHz}$ towards lower frequencies when $D_{H}$ increases (Figure 5d). Again, $\chi$ ' and $\chi$ ', show a trend with $D_{H}$ that matches the observation in live cells (solid green line), suggesting that IONPs aggregation and cell internalization lead to similar effects on the dynamical magnetic response of the IONPs.

\section{Numerical simulations of the dynamical response of IONPs}

In order to quantify the experimental observations discussed above, we performed numerical simulations based on: i) a least-squares fit routine to match generalized Debye equations to $\mathrm{ACS}$ measurements ${ }^{50}$ using a trust region reflective algorithm, ${ }^{51}$ and ii) micromagnetic simulations of the AC hysteresis loops, by solving the stochastic LandauLifshitz-Gilbert (LLG) equations using Vinamax software. ${ }^{52}$ Both numerical models included magnetic dipolar interactions among IONPs for describing the dynamical magnetic response of IONPs when increasing aggregate size, but using different approaches 
(see Material and Methods section). Simulations precisely and quantitatively reproduced the ACS measurements of IONPs dispersed in water (see dashed lines in Figures 1ab) by using fitting parameters whose values are close to experimental ones (see table S1 and S2). Indeed, the effective anisotropy values $\left(K_{\text {eff }}\right)$ equal to $4.7 \mathrm{~kJ} / \mathrm{m}^{3}$ for $11 \mathrm{~nm}$ and $21 \mathrm{~nm}$ (Table S1) are much lower than in bulk iron oxides, but close to the $K_{\text {eff }}$ values derived from the Stoner-Wohlfarth model $\left(K_{\text {eff }}=H_{C} M_{S} / 2\right)$ using the experimental $H_{C}$ and $M_{S}$ values (see Fig. S9) at low temperatures: $K_{\text {eff }}=4.7$ and $4.1 \mathrm{~kJ} / \mathrm{m}^{3}$ for $11 \mathrm{~nm}$ and $21 \mathrm{~nm} .{ }^{39}$ These values are comparable to recently reported ones obtained from similar IONPs under AC magnetic field conditions ${ }^{53-55}$. Furthermore, the slight particle aggregation already existing in water dispersions for both IONP sizes (z- average hydrodynamic sizes $=50$ and $67 \mathrm{~nm}$ for 11 and $21 \mathrm{~nm}$, respectively) could also explain the low $K_{\text {eff }}$ values in comparison to bulk maghemite. Inside cells, ACS fits obtained for the same IONPs indicate that $K_{\text {eff }}$ values noticeably diminish to from 4.7 to $2.9 \mathrm{~kJ} / \mathrm{m}^{3}$ for $11 \mathrm{~nm}$ and from 4.1 to $1.8 \mathrm{~kJ} / \mathrm{m}^{3}$ for $21 \mathrm{~nm}$ IONPs. Hence, the influence of cell uptake on the ACS response is to drastically reduce $K_{\text {eff }}$ values, independently of nanoparticle size. In addition, we simulated the AC hysteresis loops of $11 \mathrm{~nm}$ IONPs in water dispersion and inside cells (Figure 1c). Interestingly, the reducing trend of $K_{\text {eff }}$ when IONPs are inside cells obtained for fitting ACS data is in good agreement with the simulation of the AC magnetization loops (see dotted lines in Figures 1c). Such AC hysteresis loop fitting requires a reduction of $K_{\text {eff }}$ from $3.4 \mathrm{~kJ} / \mathrm{m}^{3}$ (in water) to $2.9 \mathrm{~kJ} / \mathrm{m}^{3}$ (inside live cells). In order to understand the underlying mechanisms behind the suppression of $K_{\text {eff, }}$ we performed ACS simulations considering variations of medium viscosity and IONPs aggregation (and in consequence, magnetic dipolar interactions). From the modeling of the viscosity data set, we model the contribution of Néel and Brownian 
relaxation processes of the 11 and $21 \mathrm{~nm}$ IONPs (see dotted lines in Figure 3b,d) to the AC magnetic response. Additionally, the fit of aggregation ACS data set (Fig. 5b,d) provides significant information for understanding the influence of cell uptake on the dynamical magnetic response of the studied IONPs. These simulations can be done for both IONP sizes by employing similar $K_{\text {eff }}$ fitting parameters than in water and just varying the viscosity value (see Table S1b).

As shown above in Figure 5, the ACS and ACM aggregation data series show a trend that merges to the IONP results measured in cells, for both IONP sizes. In this case, the numerical simulation of the ACS measurements describes a decreasing tendency of $K_{\text {eff }}$ concomitantly related to the increase of $D_{H}$ and polydispersity (see Table S2). On one hand, the increase of $D_{H}$ implies larger hydrodynamic volume $\left(V_{H}\right)$, which modulates the Brownian relaxation time $\left(\tau_{B}=\frac{3 \eta V_{H}}{k_{B} T}\right)$, and therefore shifts the Brownian peak of $\chi$ "' to lower frequencies. On the other hand, the increase of aggregation degree favor the magnetic dipole-dipole interactions, which can be simplified as resulting in the influence of the $K_{\text {eff }}$ value, and consequently, the Néel relaxation time $\left(\tau_{\mathrm{N}}=\frac{\sqrt{\pi}}{2 \sqrt{\mathrm{K}_{\mathrm{eff}} \mathrm{V} / \mathrm{k}_{\mathrm{B}} \mathrm{T}}} \tau_{0} \mathrm{e}^{-\mathrm{K}_{\mathrm{eff}} \mathrm{V} / \mathrm{k}_{\mathrm{B}} \mathrm{T}}\right)$. 32

The assumptions employed for modeling ACM and ACS results -i.e. variations in $V_{H}$ and $K_{\text {eff, }}$, the later mediated by magnetic dipole-dipole interactions- lead to a good agreement of numerical simulations with the experimental results. It is worth to note the different influence of the IONP aggregation increase on the dynamical magnetic response depending on the prevalent relaxation mechanism. On one hand, these simulations point out that the increase of $V_{H}$ mainly influences the magnetic response of the larger $(21 \mathrm{~nm})$ IONPs via the 
Brownian relaxation time, which is highly sensible to changes in the hydrodynamic size. On the other hand, the variation of $K_{\text {eff }}$-related to magnetic dipole-dipole interactions- is required to model the aggregation dependence of ACS results for both IONP sizes (see Table S2). Additionally, the fitting parameter related to the size polydispersity index (PDI) of the aggregates increased in a similar way to the experimental values determined by DLS or derived from TEM images of subcellular vesicles showing a large distribution of vesicle sizes (see Figures 2b,e).

According to previous studies, ${ }^{32,56}$ the influence of intra-aggregate magnetic dipoledipole interactions on the dynamical hysteresis loops of IONPs was found to be highly dependent on the spatial arrangement of the nanoparticles inside the aggregate. Most of these studies correlate random spatial arrangements of MNP into clusters ${ }^{57}$ with demagnetizing effects. This provides a qualitative explanation for the effects of hydrodynamic size on the intra-aggregate dipolar interactions, and consequently on the $K_{\text {eff }}$ value. On one hand, at the limit of a high values of $D_{H}$, the number of local particle neighbors per aggregate increases, leading to no intrinsic preferential directions of the magnetic anisotropy to align with field orientation. Therefore, a decrease of energy barrier takes place, allowing that a part of the particle magnetic moments of the aggregate follows the external AC magnetic field. This results in the decrease in the area of the hysteresis loop and the lowering of the SAR. On the other hand, at the limit of a low values of $D_{H}$, the number of local particle neighbors per aggregate is lower and hence, an intrinsic preferential direction of the magnetic anisotropy appears favoured by its particular spatial arrangement. ${ }^{58}$ Noticeably, cellular TEM images (Fig. 2 b, e) corroborate a random IONP intracellular agglomeration inside cells vesicles, reinforcing our hypothesis. 


\section{CONCLUSIONS}

We investigated the influence of cell uptake of IONPs on their dynamical magnetic response by ACS and ACM. We set a suitable methodology for testing the influence of biological environments on the dynamical magnetic response, including magnetic heat losses of magnetic nanostructures based on viscosity and aggregation studies. The comparison of these measurements of IONPs between colloidaly dispersed and inside live cells point out that the increase of intracellular IONP clustering, favoring magnetic dipolar interactions, provides the major contribution to the intracellular variation of the studied IONP magnetic response rather than the nanoparticle immobilization. Moreover, AC magnetometry probes the magnetic heat losses of IONPs inside live cells without affecting their viability. Furthermore, ACS measurements reveal that the influence of the cell internalization on dynamic magnetic response of IONPs depends on their size, environmental viscosity, and aggregation state. Numerical simulations support the conclusion that magnetic dipolar interactions, taking place within randomly ordered IONP clusters, play a central role in the $50 \%$ decrease of magnetic heating losses observed when the $21 \mathrm{~nm}$ IONPs were aggregated inside live cells. Understanding the effects related to the intracellular nanoparticle transit on their magnetic response will allow the design of nanostructures whose dynamical magnetic response (i.e. magnetic heating losses and MPI signal) will remain invariable in any biological environments. Such achievement will favor the transfer of magnetic hyperthermia mediated by MNPs and MPI to clinics.

\section{MATERIALS AND METHODS}

\section{Iron Oxide Nanoparticles}


The $11 \mathrm{~nm}$ core size magnetite IONPs, coated with citrate, are commercial IONPs (fluidMAG-CT, product number: 4122-5, hydrodynamic diameter 50nm) produced by Chemicell GmbH, Berlin (Germany). The $21 \mathrm{~nm}$ core size maghemite IONPs are commercial maghemite powder (Iron(III) oxide, $<50 \mathrm{~nm}$ particle size, Sigma reference 544884-25G) produced and distributed by at Sigma-Aldrich Corporation, Saint Louis, USA. Later on, these IONPs were coated with citrate according to Răcicu et al. protocol. ${ }^{59}$ Both IONP stocks were sterilized via microfiltration $(0.22 \mu \mathrm{m}$ Millipore $)$ before their use in all the experiments.

\section{Colloidal Characterization}

Hydrodynamic sizes $\left(D_{H}\right)$ of the IONPs dispersed in $\mathrm{ddH}_{2} \mathrm{O}$ and $36 \%$ glycerol $\left(\mathrm{v} / \mathrm{v}_{\mathrm{w}}\right)$ were determined by Dynamic Light Scattering in a Zetasizer-ZS (Malvern) at a final concentration of $0.02 \mathrm{~g}_{\mathrm{Fe}} / \mathrm{L}$. A laser emitting red light at $633 \mathrm{~nm}$ acted as energy source, $173^{\circ}$ was the angle between the sample and the detector and $40 \mu \mathrm{L}$ disposable cuvette were employed.

For the IONPs aggregation studies, hydrodynamic size $\left(D_{H}\right)$ raises were induced through the addition of increasing fractions of Fetal Bovine Serum (FBS) to the dispersion (See Table S2 for used FBS volume fractions). During the magnetic measurements, the hydrodynamic size of these dispersions was monitored in a Zetasizer 3000 using a quartz cuvette at a final concentration of $0.02 \mathrm{~g}_{\mathrm{Fe}} / \mathrm{L}$. Cumulant method (z-average) was used for the determination of $\mathrm{D}_{\mathrm{H}}$ average. Raw data was also number weighted for the comparison with theoretical data (Table S2).

\section{Iron quantification}


Iron quantification of the IONP concentration in aqueous and cell dispersions were performed with ICP-OES and ICP-MS at Instituto de Ciencia de Materiales-CSIC, Ciudad Universitaria de Cantoblanco, Madrid (Spain). $25 \mu \mathrm{L}$ of iron oxide nanoparticles were digested in aqua regia $(\mathrm{HNO} 3+3 \mathrm{HCl})$ at room temperature under sonication and diluted 1:1000 in water. Cells were digested in acid media 36.6-38\% $\mathrm{HCl}$ (Sigma) for 30 minutes under sonication at $40^{\circ} \mathrm{C}$. Afterwards, they were kept at room temperature overnight and finally diluted 1:1000 in water.

\section{Cell culture experiments}

Around 1.5 million MCF-7 (HTB-22) breast cancer cells, purchased from the LGC Standards (Middlesex, UK); were seeded in T175 flasks DMEM (Sigma) supplemented with 10\% FBS, $100 \mathrm{IU} / \mathrm{ml}$ penicillin and 100g/L streptomycin (Lonza) and $2 \mathrm{mM} \mathrm{L-}$ Glutamine (Lonza) was used as cell culture media. The cells were incubated at $37^{\circ} \mathrm{C}$ in air

atmosphere with 5\% CO2. After 48 hours, the culture media were substituted for a suspension of $0.1 \mathrm{~g}_{\mathrm{Fe}} / \mathrm{L}$ IONPs in fresh media for 24 hours. At this point, the cells were washed with PBS (Sigma) five times to remove all non-internalized IONPs, detached with trypsin (Lonza), pelletized and resuspended in $200 \mu \mathrm{L}$ of supplemented media. AC magnetic measurements (susceptometry and magnetometry) were performed immediately after. Once the measurements were finished, one fifth of the cell pellet was reseeded onto P35 plates, onto glass cover slides and directly onto 24-multiwell plates. After 12 hours, the cells became adherent and they were separated in 5 sets for microscopy studies. The rest of the cell suspensions were digested to quantify the iron content.

\section{Prussian Blue Staining}


Cells were fixed on 24-multiwell incubating with methanol for 15 minutes at room temperature. Next, the fixative was removed, and the cultures were washed twice with $\mathrm{ddH}_{2} \mathrm{O}$. Then, the wells were treated with solutions of $20 \%$ aqueous solution of hydrochloric acid (v/v) and 10\% of potassium ferrocyanide (w/v) (Sigma) for 20 minutes at room temperature. The washing step was repeated, and the cell monolayers were treated with Nuclear Fast Red (Sigma) for 5 minutes. Finally, the wells were washed three times with $\mathrm{ddH}_{2} \mathrm{O}$ and observed under inverted microscope (EVO) with bright field configuration. For staining-free cells, only the fixation procedure was performed.

\section{Confocal microscopies}

Cells were fixed onto 24-wells cover slips via incubation with cold ethanol during 5 minutes at $-20^{\circ} \mathrm{C}$. Next, the coverslips were washed twice with PBS and stained first with ActinRed ${ }^{(M o l e c u l a r}$ Probes) and DAPI. Finally, the cover slips were mounted onto microscope slides and vertical micrographs sections with a $300 \mathrm{~nm}$ step were taken with Olympus U-TBI 90 Microscope. For cell viability, cover slips were treated with LIVE/DEAD® calcein AM/ethidium homodimer-1 viability/cytotoxicity kit (Molecular Probes $^{\mathrm{TM}}$ ), mounted onto microscope slides and sealed with nail varnish.

\section{Transmision Electron Microscopy}

Transmission Electron Microscopy images of cell cultures were performed in Servicio de Microscopía Electrónica del Centro de Biología Molecular "Severo Ochoa" in a Jeol JEM1010 microscope equipped with a CMOS 4K x 4K, F416 de TVIPS camera. Cells were fixed on P35 Petri dishes with 2\% glutaraldehyde (Sigma) in PBS for two hours at room temperature. Once the fixation was finished, the fixative was retired and the dishes were rinsed with PBS three times. Next, the cultures were treated sequentially with a solution of 
$1 \%$ sodium tetraoxide plus $1 \%$ of potassium ferrocyanide in $\mathrm{ddH} 2 \mathrm{O}$ for 1 hour; $0.15 \%$ of tannic acid in $1 \mathrm{M}$ phosphate buffer $\mathrm{pH} 7.4$ for 1 minute and $2 \%$ of Uranyl Acetate in ddH2O for 1 hour. Finally, the samples were dehydrated with EtOH in various steps with crescent concentration and infiltrated with TAAB 812 epoxy resin. After the polymerization is finished, ultrafine slides $(60-70 \mathrm{~nm})$ were made with ultramicrotome Leica Ultracut, placed on $\mathrm{Cu} / \mathrm{Pd}$ grides and dyed with $2 \%$ uranyl acetate and plumb citrate.

\section{Magnetic characterization}

Quasi-static conditions: Magnetization cycles under quasi-static conditions were carried out at different temperatures between 10 and $260 \mathrm{~K}$ in an ever-cooled Magnetic Property Measurement System (MPMS-XL, Quantum Design) on MNP dispersion volumes of $60 \mu \mathrm{L}$ at concentration of $1 \mathrm{~g}_{\mathrm{Fe}} / \mathrm{L}$ (Figure S9). The magnetization signal was normalized to the mass of the magnetic material.

Dynamical conditions: AC hysteresis loops were traced with a home-made inductive magnetometer based on the one described by Connord et $\mathrm{al}^{36}$, operating at room temperature. The magnetic field are generated by a Litz wire solenoid, inside which two counterwise-wounded coils compensated with the same diameter and number of turns collect the induction signal of the sample. The AC magnetization signal was normalized to the mass of magnetic material. Cells are exposed to a magnetic hyperthermia field for a short period of time $(<5 \mathrm{~s})$ and kept at $25^{\circ} \mathrm{C}$ for 5 minutes, resulting in non-appreciable effect in cell viability after their reseeding $12 \mathrm{~h}$ after the experiment (Figure 2-S2-S3).

AC magnetic susceptibility: ACS was measured in a home-made AC susceptometer on $200 \mu 1$ of the sample at $37^{\circ} \mathrm{C}$. An oscillating magnetic field $(\operatorname{Hmax} \sim 0.4 \mathrm{kA} / \mathrm{m})$ was applied from $10 \mathrm{~Hz}$ to $520 \mathrm{kHz}$ and the induction signal was monitored via two counter-wise pick- 
up coil. After a background subtraction, the real and the imaginary part of the susceptibility is calculated for every frequency. In order to preserve the cell integrity, all the susceptibility measurements were performed at $37{ }^{\circ} \mathrm{C}$. Due to the IONP induction signal fall provoked by physiological media and cells in some IONPs, the measurements were limited up to 40 $\mathrm{kHz}$.

Determination of specific absorption rate: The specific absorption rate (SAR) on the studied IONPs was determined as follows: AC hysteresis loops were measured three times and averaged. Afterwards, the area was extracted from the averaged curve and SAR value was calculated according to $\mathrm{SAR}=\mathrm{A} \cdot \mathrm{f},{ }^{37}$ where $\mathrm{f}$ is field frequency.

\section{ACS and ACM numerical modelling}

The ACS measurements were fitted to a generalized Debye model. ${ }^{50}$ This model depends, among others, on the distribution function of the core and hydrodynamic diameters of the particles $\left(f\left(\mathrm{D}_{\mathrm{C}}\right)\right)$ and $\left(f\left(\mathrm{D}_{\mathrm{H}}\right)\right)$, their anisotropy $\left(\mathrm{K}_{\text {eff }}\right)$ and the viscosity of the particles' environment $(\eta) . f\left(\mathrm{D}_{\mathrm{C}}\right)$ was obtained from TEM measurements of the particles. Hence, the remaining fit parameters are $f\left(\mathrm{D}_{\mathrm{H}}\right), \eta$ and $\mathrm{K} . f\left(\mathrm{D}_{\mathrm{H}}\right)$ reflects the possible aggregation of the particles and $\mathrm{K}_{\text {eff }}$ additionally includes possible particle interactions. The fits were performed using a multi-start procedure to reduce chances on overfitting. ACS simulations were done on the frequency range where data are reliable (see the magnetic characterization section of the supporting information). For the sake of comparison, experimental data are shown in the same frequency range where the data is reliable. Furthermore, for each measurement varying sets of fit parameters were employed to investigate convergence of the fit. The final fits used in this study were obtained as follows; in case of the particles submerged in water, $\eta$ was set at $0.71 \mathrm{mPa} \cdot \mathrm{s}$. For the viscosity series $f\left(\mathrm{D}_{\mathrm{H}}\right)$ was fixed to the 
distribution found from the particles in water. In case of the aggregation series and the particles embedded in cells, the particle cores in the aggregates start to interact, affecting the $\mathrm{K}$ value of the particles and changing the amplitude of the magnetic susceptibility. The difference in amplitude between actual and modelled susceptibility can be interpreted as an interaction value. ${ }^{60}$ Therefore, an additional fit parameter was introduced to take into account the changing amplitude and $\eta$ was fixed to $0.7 \mathrm{mPa} \cdot \mathrm{s}$.

The micromagnetic simulations of the hysteresis loop were performed using Vinamax. ${ }^{52}$ In these simulations the magnetization dynamics of an ensemble of 20000 particles with a lognormal size distribution obtained from TEM images, saturation magnetization=360 $\mathrm{kA} / \mathrm{m}$ and uniaxial anisotropy constant $\mathrm{K}=3.4 \mathrm{~kJ} / \mathrm{m}^{3}$ (with random anisotropy axes) were investigated in an externally applied sinusoidal field with an amplitude of $20 \mathrm{kA} / \mathrm{m}$ and a frequency of $100 \mathrm{kHz}$. The micromagnetic damping parameter was estimated at 0.0015 in agreement with earlier measurements ${ }^{61}$ and interactions were taken into account by a meanfield approach, calculated as a percentage (the interaction strength) of the demagnetizing field resulting from the nonzero magnetization of the ensemble as a whole. Vinamax does not take into account particle rotations, and hence does not allow to consider Brownian relaxation process in the simulations. Hence, it is not possible to simulate the hysteresis loops of the $21 \mathrm{~nm}$ particles with Vinamax.

\section{AUTHOR INFORMATION}

\section{Corresponding Authors}

* Neil D. Telling: n.d.telling@keele.ac.uk 
**Francisco J. Teran: francisco.teran@imdea.org

\section{Author Contributions}

DC, NDT, and FJT designed the experiments. EJAI developed the AC magnetometer. DC performed the experiments. AC, JL, and LD performed the simulations. DC and FJT wrote the manuscript, which received contributions from all authors. All authors have given approval to the final version of the manuscript.

\section{Funding Sources}

European Commission: H2020 NOCANTHER, GA number 685795; FP7 Mag(net)icFun PITN-GA-2012-290248, and COST Action TD1402 (RADIOMAG).

Engineering \& Physical Sciences Research Council (United Kingdom): EP/P011403/1.

Spanish Ministry of Economy and Competitiveness: MAT2013-47395-C4-3-R, RYC-201109617, MAT2016-81955-REDT, SEV-2016-0686.

Madrid Region: NANOFRONTMAG-CM, S2013/MIT-2850.

Research Foundation - Flanders (FWO) and Ghent University Special Research Fund.

\section{ACKNOWLEDGMENTS}

Authors are deeply acknowledged to the funding by European Commission (H2020 NOCANTHER, GA number 685795; FP7 Mag(net)icFun PITN-GA-2012-290248), the

Engineering \& Physical Sciences Research Council (United Kingdom, Project, EP/P011403/1), Spanish Ministry of Economy and Competitiveness (MAT2013-47395-C43-R, MAT2016-81955-REDT, SEV-2016-0686) and Comunidad de Madrid 
(NANOFRONTMAG-CM, S2013/MIT-2850). The European COST Action TD1402 (RADIOMAG), and Ramon y Cajal subprogram (RYC-2011-09617) are also acknowledged. K. Narayanasamy, C. Hoskins, the Advanced Instrumentation and Cell Unit of iMdea Nanociencia (A. Arnáiz and A. Pizarro) are acknowledged for technical assistance. A. Bollero, E. Cespedes and Centro de Apoyo a la Investigación (Técnicas Físicas) de la Universidad Complutense de Madrid are acknowledged for SQUID measurements. A.C. and J. L. are supported by the Research Foundation - Flanders (FWO) and Ghent University Special Research Fund (BOF), respectively, through a postdoctoral fellowship.

\section{ASSOCIATED CONTENT}

Supporting Information. Morphological and colloidal characterization of IONPs. Cells bright field images. Live/Dead® Test. Analysis of the characteristic parameters of the hysteresis loops. Extended magnetic experimental and theoretical data. This data is included in a PDF file. This material is available free of charge via the Internet at http://pubs.acs.org.

\section{REFERENCES}

1. Aires, A.; Ocampo, S. M.; Simões, B. M.; Rodríguez, M. J.; Cadenas, J. F.; Couleaud, P.; Spence, K.; Latorre, A.; Miranda, R.; Somoza, A.; Clarke, R. B.; Carrascosa, J. L.; Cortajarena, A. L., Multifunctionalized Iron Oxide Nanoparticles for Selective Drug Delivery to Cd44-Positive Cancer Cells. Nanotechnology 2016, 27, 065103. 
2. Dobson, J., Gene Therapy Progress and Prospects: Magnetic Nanoparticle-Based Gene Delivery. Gene Ther. 2006, 13, 283-287.

3. Leong, S. S.; Yeap, S. P.; Lim, J. K., Working Principle and Application of Magnetic Separation for Biomedical Diagnostic at High- and Low-Field Gradients. Interface Focus 2016, 6.

4. Rocha-Santos, T. A. P., Sensors and Biosensors Based on Magnetic Nanoparticles. Trends Anal. Chem. 2014, 62, 28-36.

5. Bauer, L. M.; Situ, S. F.; Griswold, M. A.; Samia, A. C. S., Magnetic Particle Imaging Tracers: State-of-the-Art and Future Directions. J. Phys. Chem. Lett. 2015, 6, 2509-2517.

6. Wang, Y.-X. J., Superparamagnetic Iron Oxide Based MRI Contrast Agents: Current Status of Clinical Application. Quant. Imaging Med. Surg. 2011, 1, 35-40.

7. Espinosa, A.; Di Corato, R.; Kolosnjaj-Tabi, J.; Flaud, P.; Pellegrino, T.; Wilhelm, C., Duality of Iron Oxide Nanoparticles in Cancer Therapy: Amplification of Heating Efficiency by Magnetic Hyperthermia and Photothermal Bimodal Treatment. ACS Nano 2016, 10, 2436-2446.

8. Maier-Hauff, K.; Ulrich, F.; Nestler, D.; Niehoff, H.; Wust, P.; Thiesen, B.; Orawa, H.; Budach, V.; Jordan, A., Efficacy and Safety of Intratumoral Thermotherapy Using Magnetic Iron-Oxide Nanoparticles Combined with External Beam Radiotherapy on Patients with Recurrent Glioblastoma Multiforme. J. Neurooncol. 2011, 103, 317-324. 
9. Salas, G.; Camarero, J.; Cabrera, D.; Takacs, H.; Varela, M.; Ludwig, R.; Dähring, H.; Hilger, I.; Miranda, R.; Morales, M. d. P.; Teran, F. J., Modulation of Magnetic Heating Via Dipolar Magnetic Interactions in Monodisperse and Crystalline Iron Oxide Nanoparticles. J. Phys. Chem. C 2014, 118, 19985-19994.

10. Blanco-Andujar, C.; Walter, A.; Cotin, G.; Bordeianu, C.; Mertz, D.; Felder-Flesch, D.; Begin-Colin, S., Design of Iron Oxide-Based Nanoparticles for MRI and Magnetic Hyperthermia. Nanomedicine 2016, 11, 1889-1910.

11. Guardia, P.; Di Corato, R.; Lartigue, L.; Wilhelm, C.; Espinosa, A.; GarciaHernandez, M.; Gazeau, F.; Manna, L.; Pellegrino, T., Water-Soluble Iron Oxide Nanocubes with High Values of Specific Absorption Rate for Cancer Cell Hyperthermia Treatment. ACS Nano 2012, 6, 3080-3091.

12. Guardia, P.; Riedinger, A.; Nitti, S.; Pugliese, G.; Marras, S.; Genovese, A.; Materia, M. E.; Lefevre, C.; Manna, L.; Pellegrino, T., One Pot Synthesis of Monodisperse Water Soluble Iron Oxide Nanocrystals with High Values of the Specific Absorption Rate. J.Mater.Chem. B 2014, 2, 4426-4434.

13. Arami, H.; Khandhar, A.; Liggitt, D.; Krishnan, K. M., In Vivo Delivery, Pharmacokinetics, Biodistribution and Toxicity of Iron Oxide Nanoparticles. Chem. Soc. Rev. 2015, 44, 8576-8607.

14. Périgo, E. A.; Hemery, G.; Sandre, O.; Ortega, D.; Garaio, E.; Plazaola, F.; Teran, F. J., Fundamentals and Advances in Magnetic Hyperthermia. Appl. Phys.Rev. 2015, 2, 041302. 
15. Arami, H.; Khandhar, A. P.; Tomitaka, A.; Yu, E.; Goodwill, P. W.; Conolly, S. M.; Krishnan, K. M., In Vivo Multimodal Magnetic Particle Imaging (MPI) with Tailored Magneto/Optical Contrast Agents. Biomaterials 2015, 52, 251-261.

16. Sathya, A.; Guardia, P.; Brescia, R.; Silvestri, N.; Pugliese, G.; Nitti, S.; Manna, L.; Pellegrino, T., $\mathrm{Co}_{\mathrm{x}} \mathrm{Fe}_{3-\mathrm{x}} \mathrm{O}_{4}$ Nanocubes for Theranostic Applications: Effect of Cobalt Content and Particle Size. Chem. Mater. 2016, 28, 1769-1780.

17. Di Corato, R.; Espinosa, A.; Lartigue, L.; Tharaud, M.; Chat, S.; Pellegrino, T.; Ménager, C.; Gazeau, F.; Wilhelm, C., Magnetic Hyperthermia Efficiency in the Cellular Environment For different Nanoparticle Designs. Biomaterials 2014, 35, 6400-6411.

18. Soukup, D.; Moise, S.; Céspedes, E.; Dobson, J.; Telling, N. D., In Situ Measurement of Magnetization Relaxation of Internalized Nanoparticles in Live Cells. ACS Nano 2015, 9, 231-240.

19. Moise, S.; Céspedes, E.; Soukup, D.; Byrne, J. M.; El Haj, A. J.; Telling, N. D., The Cellular Magnetic Response and Biocompatibility of Biogenic Zinc- and Cobalt-Doped Magnetite Nanoparticles. Sci.Rep. 2017, 7.

20. Mazuel, F.; Espinosa, A.; Luciani, N.; Reffay, M.; Le Borgne, R.; Motte, L.; Desboeufs, K.; Michel, A.; Pellegrino, T.; Lalatonne, Y.; Wilhelm, C., Massive Intracellular Biodegradation of Iron Oxide Nanoparticles Evidenced Magnetically at Single-Endosome and Tissue Levels. ACS Nano 2016, 10, 7627-7638. 
21. Lévy, M.; Gazeau, F.; Bacri, J.-C.; Wilhelm, C.; Devaud, M., Modeling Magnetic Nanoparticle Dipole-Dipole Interactions inside Living Cells. Phys. Rev. B 2011, 84, 075480.

22. Levy, M.; Wilhelm, C.; Luciani, N.; Deveaux, V.; Gendron, F.; Luciani, A.; Devaud, M.; Gazeau, F., Nanomagnetism Reveals the Intracellular Clustering of Iron Oxide Nanoparticles in the Organism. Nanoscale 2011, 3, 4402-4410.

23. Lévy, M.; Wilhelm, C.; Devaud, M.; Levitz, P.; Gazeau, F., How Cellular Processing of Superparamagnetic Nanoparticles Affects Their Magnetic Behavior and NMR Relaxivity. Contrast Media Mol. Imaging 2012, 7, 373-383.

24. Kuimova, M. K.; Botchway, S. W.; Parker, A. W.; Balaz, M.; Collins, H. A.; Anderson, H. L.; Suhling, K.; Ogilby, P. R., Imaging Intracellular Viscosity of a Single Cell During Photoinduced Cell Death. Nat. Chem. 2009, 1, 69-73.

25. Kuimova, M. K.; Yahioglu, G.; Levitt, J. A.; Suhling, K., Molecular Rotor Measures Viscosity of Live Cells Via Fluorescence Lifetime Imaging. J. Am. Chem. Soc. 2008, 130, 6672-6673.

26. Arami, H.; Krishnan, K. M., Intracellular Performance of Tailored Nanoparticle Tracers in Magnetic Particle Imaging. J. Appl. Phys. 2014, 115.

27. Sanz, B.; Calatayud, M. P.; De Biasi, E.; Lima Jr, E.; Mansilla, M. V.; Zysler, R. D.; Ibarra, M. R.; Goya, G. F., In Silico before In Vivo: How to Predict the Heating Efficiency of Magnetic Nanoparticles within the Intracellular Space. Sci. Rep. 2016, 6, 38733. 
28. Panagiotopoulos, N.; Duschka, R. L.; Ahlborg, M.; Bringout, G.; Debbeler, C.; Graeser, M.; Kaethner, C.; Lüdtke-Buzug, K.; Medimagh, H.; Stelzner, J.; Buzug, T. M.; Barkhausen, J.; Vogt, F. M.; Haegele, J., Magnetic Particle Imaging: Current Developments and Future Directions. Int. J. Nanomed. 2015, 10, 3097-3114.

29. Weizenecker, J.; Gleich, B.; Rahmer, J.; Dahnke, H.; Borgert, J., ThreeDimensional Real-Time In Vivo Magnetic Particle Imaging. Phys. Med. Biol. 2009, 54, L1.

30. Dieckhoff, J.; Eberbeck, D.; Schilling, M.; Ludwig, F., Magnetic-Field Dependence of Brownian and Néel Relaxation Times. J. Appl. Phys. 2016, 119, 043903.

31. Conde-Leboran, I.; Baldomir, D.; Martinez-Boubeta, C.; Chubykalo-Fesenko, O.; del Puerto Morales, M.; Salas, G.; Cabrera, D.; Camarero, J.; Teran, F. J.; Serantes, D., A Single Picture Explains Diversity of Hyperthermia Response of Magnetic Nanoparticles. J. Phys. Chem. C 2015, 119, 15698-15706.

32. Ovejero, J. G.; Cabrera, D.; Carrey, J.; Valdivielso, T.; Salas, G.; Teran, F. J., Effects of Inter- and Intra-Aggregate Magnetic Dipolar Interactions on the Magnetic Heating Efficiency of Iron Oxide Nanoparticles. Phys. Chem. Chem. Phys. 2016, 18, 10954-10963.

33. Jordan, A.; Wust, P.; Fählin, H.; John, W.; Hinz, A.; Felix, R., Inductive Heating of Ferrimagnetic Particles and Magnetic Fluids: Physical Evaluation of Their Potential for Hyperthermia. Int. J. Hyperthermia 1993, 9, 51-68. 
34. Wildeboer, R. R.; Southern, P.; Pankhurst, Q. A., On the Reliable Measurement of Specific Absorption Rates and Intrinsic Loss Parameters in Magnetic Hyperthermia Materials. J. Phys. D: Appl. Phys. 2014, 47, 495003.

35. Wang, S. Y.; Huang, S.; Borca-Tasciuc, D. A., Potential Sources of Errors in Measuring and Evaluating the Specific Loss Power of Magnetic Nanoparticles in an Alternating Magnetic Field. IEEE Trans. Mag. 2013, 49, 255-262.

36. Connord, V.; Mehdaoui, B.; Tan, R. P.; Carrey, J.; Respaud, M., An Air-Cooled Litz Wire Coil for Measuring the High Frequency Hysteresis Loops of Magnetic Samples-a Useful Setup for Magnetic Hyperthermia Applications. Rev. Sci. Instrum. 2014, 85, 093904.

37. Mehdaoui, B.; Carrey, J.; Stadler, M.; Cornejo, A.; Nayral, C.; Delpech, F.; Chaudret, B.; Respaud, M., Influence of a Transverse Static Magnetic Field on the Magnetic Hyperthermia Properties and High-Frequency Hysteresis Loops of Ferromagnetic Feco Nanoparticles. Appl. Phys. Lett. 2012, 100, 052403.

38. Cabrera, D.; Lak, A.; Yoshida, T.; Materia, M. E.; Ortega, D.; Ludwig, F.; Guardia, P.; Sathya, A.; Pellegrino, T.; Teran, F. J., Unraveling Viscosity Effects on the Hysteresis Losses of Magnetic Nanocubes. Nanoscale 2017, 9, 5094-5101.

39. Cespedes, E.; Byrne, J. M.; Farrow, N.; Moise, S.; Coker, V. S.; Bencsik, M.; Lloyd, J. R.; Telling, N. D., Bacterially Synthesized Ferrite Nanoparticles for Magnetic Hyperthermia Applications. Nanoscale 2014, 6, 12958-12970. 
40. Maldonado-Camargo, L.; Torres-Díaz, I.; Chiu-Lam, A.; Hernández, M.; Rinaldi, C., Estimating the Contribution of Brownian and Néel Relaxation in a Magnetic Fluid through Dynamic Magnetic Susceptibility Measurements. J. Magn. Magn. Mater. 2016, $412,223-233$.

41. Calero, M.; Gutiérrez, L.; Salas, G.; Luengo, Y.; Lázaro, A.; Acedo, P.; Morales, M. P.; Miranda, R.; Villanueva, A., Efficient and Safe Internalization of Magnetic Iron Oxide Nanoparticles: Two Fundamental Requirements for Biomedical Applications. Nanomed. Nanotechnol. Biol. Med. 10, 733-743.

42. Creixell, M.; Bohórquez, A. C.; Torres-Lugo, M.; Rinaldi, C., EGFR-Targeted Magnetic Nanoparticle Heaters Kill Cancer Cells without a Perceptible Temperature Rise. ACS Nano 2011, 5, 7124-7129.

43. Blanco-Andujar, C.; Ortega, D.; Southern, P.; Nesbitt, S. A.; Thanh, N. T. K.; Pankhurst, Q. A., Real-Time Tracking of Delayed-Onset Cellular Apoptosis Induced by Intracellular Magnetic Hyperthermia. Nanomedicine 2015, 11, 121-136.

44. Connord, V.; Clerc, P.; Hallali, N.; El Hajj Diab, D.; Fourmy, D.; Gigoux, V.; Carrey, J., Real-Time Analysis of Magnetic Hyperthermia Experiments on Living Cells under a Confocal Microscope. Small 2015, 11, 2437-2445.

45. Kim, D.-H.; Rozhkova, E. A.; Ulasov, I. V.; Bader, S. D.; Rajh, T.; Lesniak, M. S.; Novosad, V., Biofunctionalized Magnetic-Vortex Microdiscs for Targeted Cancer-Cell Destruction. Nat. Mater. 2010, 9, 165-171. 
46. Etoc, F.; Vicario, C.; Lisse, D.; Siaugue, J.-M.; Piehler, J.; Coppey, M.; Dahan, M., Magnetogenetic Control of Protein Gradients inside Living Cells with High Spatial and Temporal Resolution. Nano Lett. 2015, 15, 3487-3494.

47. Silvio, D.; Melanie, K.; Ingrid, H.; Robert, M.; Matthias, Z., Magnetic Multicore Nanoparticles for Hyperthermia-Influence of Particle Immobilization in Tumour Tissue on Magnetic Properties. Nanotechnology 2011, 22, 265102.

48. Takashi, Y.; Keiji, E., Simulation and Quantitative Clarification of AC Susceptibility of Magnetic Fluid in Nonlinear Brownian Relaxation Region. Jpn. J. Appl. Phys. 2009, 48, 127002.

49. Chiappi, M.; Conesa, J. J.; Pereiro, E.; Sorzano, C. O. S.; Rodríguez, M. J.; Henzler, K.; Schneider, G.; Chichón, F. J.; Carrascosa, J. L., Cryo-Soft X-Ray Tomography as a Quantitative Three-Dimensional Tool to Model Nanoparticle:Cell Interaction. J. Nanobiotechnol. 2016, 14, 15.

50. Ludwig, F.; Balceris, C.; Jonasson, C.; Johansson, C., Analysis of Ac Susceptibility Spectra for the Characterization of Magnetic Nanoparticles. IEEE Trans. Mag. 2017, 53, 14.

51. Branch, M. A.; Coleman, T. F.; Li, Y., A Subspace, Interior, and Conjugate Gradient Method for Large-Scale Bound-Constrained Minimization Problems. SIAM J. Sci. Comput. 1999, 21, 1-23. 
52. Leliaert, J.; Vansteenkiste, A.; Coene, A.; Dupré, L.; Van Waeyenberge, B., Vinamax: A Macrospin Simulation Tool for Magnetic Nanoparticles. Med. Biol. Eng. Comput. 2015, 53, 309-317.

53. Ludwig, F.; Remmer, H.; Kuhlmann, C.; Wawrzik, T.; Arami, H.; Ferguson, R. M.; Krishnan, K. M., Self-Consistent Magnetic Properties of Magnetite Tracers Optimized for Magnetic Particle Imaging Measured by Ac Susceptometry, Magnetorelaxometry and Magnetic Particle Spectroscopy. J. Magn. Magn. Mater. 2014, 360, 169-173.

54. Shah, S. A.; Reeves, D. B.; Ferguson, R. M.; Weaver, J. B.; Krishnan, K. M., Mixed Brownian Alignment and Néel Rotations in Superparamagnetic Iron Oxide Nanoparticle Suspensions Driven by an AC Field. Phys. Rev. B 2015, 92, 094438.

55. Gehrke, N.; Heinke, D.; Eberbeck, D.; Ludwig, F.; Wawrzik, T.; Kuhlmann, C.; Briel, A., Magnetic Characterization of Clustered Core Magnetic Nanoparticles for MPI. IEEE Trans. Mag. 2015, 51, 1-4.

56. Etheridge, M. L.; Hurley, K. R.; Zhang, J.; Jeon, S.; Ring, H. L.; Hogan, C.; Haynes, C. L.; Garwood, M.; Bischof, J. C., Accounting for Biological Aggregation in Heating and Imaging of Magnetic Nanoparticles. Technology 2014, 02, 214-228.

57. Serantes, D.; Simeonidis, K.; Angelakeris, M.; Chubykalo-Fesenko, O.; Marciello, M.; Morales, M. d. P.; Baldomir, D.; Martinez-Boubeta, C., Multiplying Magnetic Hyperthermia Response by Nanoparticle Assembling. J. Phys. Chem. C 2014, 118, 59275934. 
58. Hovorka, O., Thermal Activation in Statistical Clusters of Magnetic Nanoparticles. J. Phys. D: Appl. Phys. 2017, 50, 044004.

59. Răcuciu, M.; Creangă, D. E.; Airinei, A., Citric-Acid-Coated Magnetite Nanoparticles for Biological Applications. Eur. Phys. J. E 2006, 21, 117-121.

60. Ahrentorp, F.; Astalan, A.; Blomgren, J.; Jonasson, C.; Wetterskog, E.; Svedlindh, P.; Lak, A.; Ludwig, F.; van Ijzendoorn, L. J.; Westphal, F.; Grüttner, C.; Gehrke, N.; Gustafsson, S.; Olsson, E.; Johansson, C., Effective Particle Magnetic Moment of MultiCore Particles. J. Magn. Magn. Mater. 2015, 380, 221-226.

61. Leliaert, J.; Coene, A.; Crevecoeur, G.; Vansteenkiste, A.; Eberbeck, D.; Wiekhorst, F.; Van Waeyenberge, B.; Dupré, L., Regarding the Néel Relaxation Time Constant in Magnetorelaxometry. J. Appl. Phys. 2014, 116. 

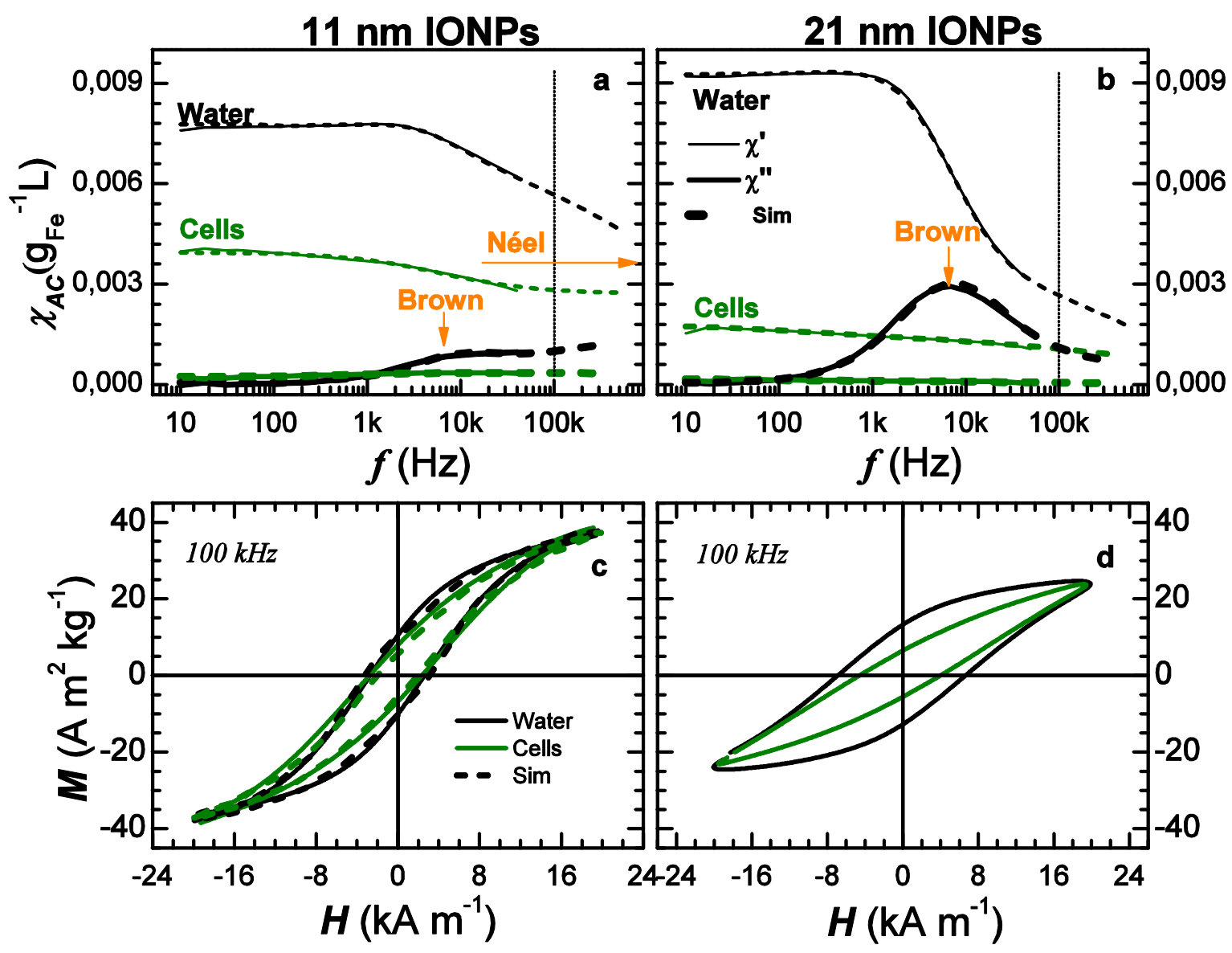

Figure 1. Experimental (solid lines) and simulated (dashed lines) AC susceptibility for a) $11 \mathrm{~nm}$ IONPs, b) $21 \mathrm{~nm}$ IONPs dispersed in water (black colour) and inside live cells (green colour); experimental (solid lines) and simulated (dashed lines) AC hysteresis curves under $H_{A C}(100 \mathrm{kHz}$ and $20 \mathrm{kA} / \mathrm{m})$ for c) $11 \mathrm{~nm}$ IONPs, d) $21 \mathrm{~nm}$ IONPs dispersed in water (black colour) and inside live cells (green colour). The iron content was $1 \mathrm{~g}_{\mathrm{F}} / \mathrm{L}$ for all measurements, except for the $21 \mathrm{~nm}$ IONPs inside live cells $\left(0.7 \mathrm{~g}_{\mathrm{Fe}} / \mathrm{L}\right)$. The vertical dotted lines in a) and b) indicate the $H_{A C}$ frequency employed in $\mathrm{AC}$ hysteresis loops measurements. 


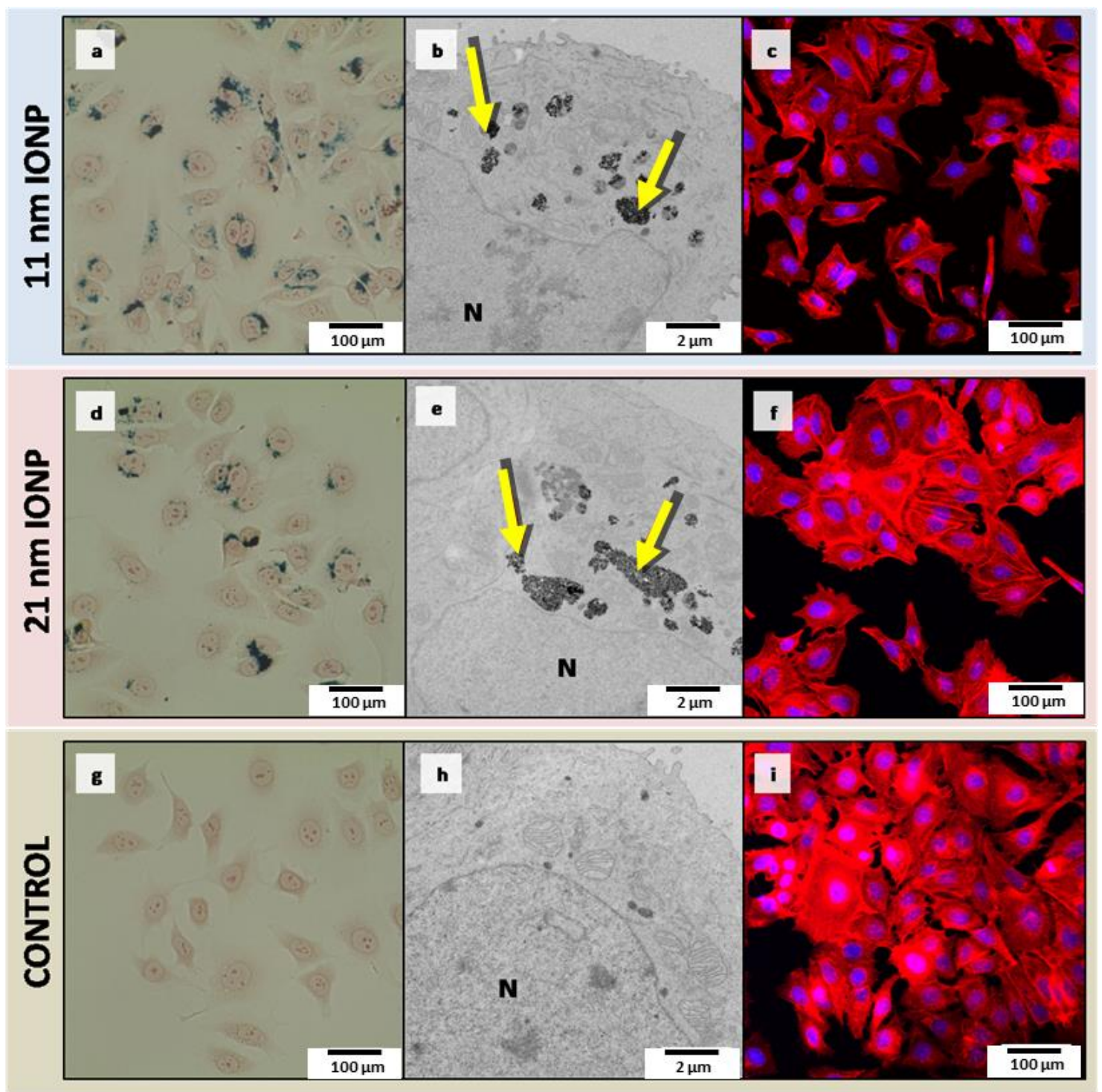

Figure 2. Representative micrographics of reseeded cells $12 \mathrm{~h}$ after magnetic measurements. a)d)g) Bright field images of Prussian Blue stained cells; scale bars 100 mm, b)e)h) Cells TEM section images; scale bars $2 \mathrm{~mm}$; yellow arrows indicate the location of IONPs. c)f)i) Cell 3D reconstructed confocal images ; scale bars $100 \mathrm{~mm}$. Cells were stained with DAPI (blue) for nucleus staining, and ActinRed ${ }^{\odot}$ for actin staining 


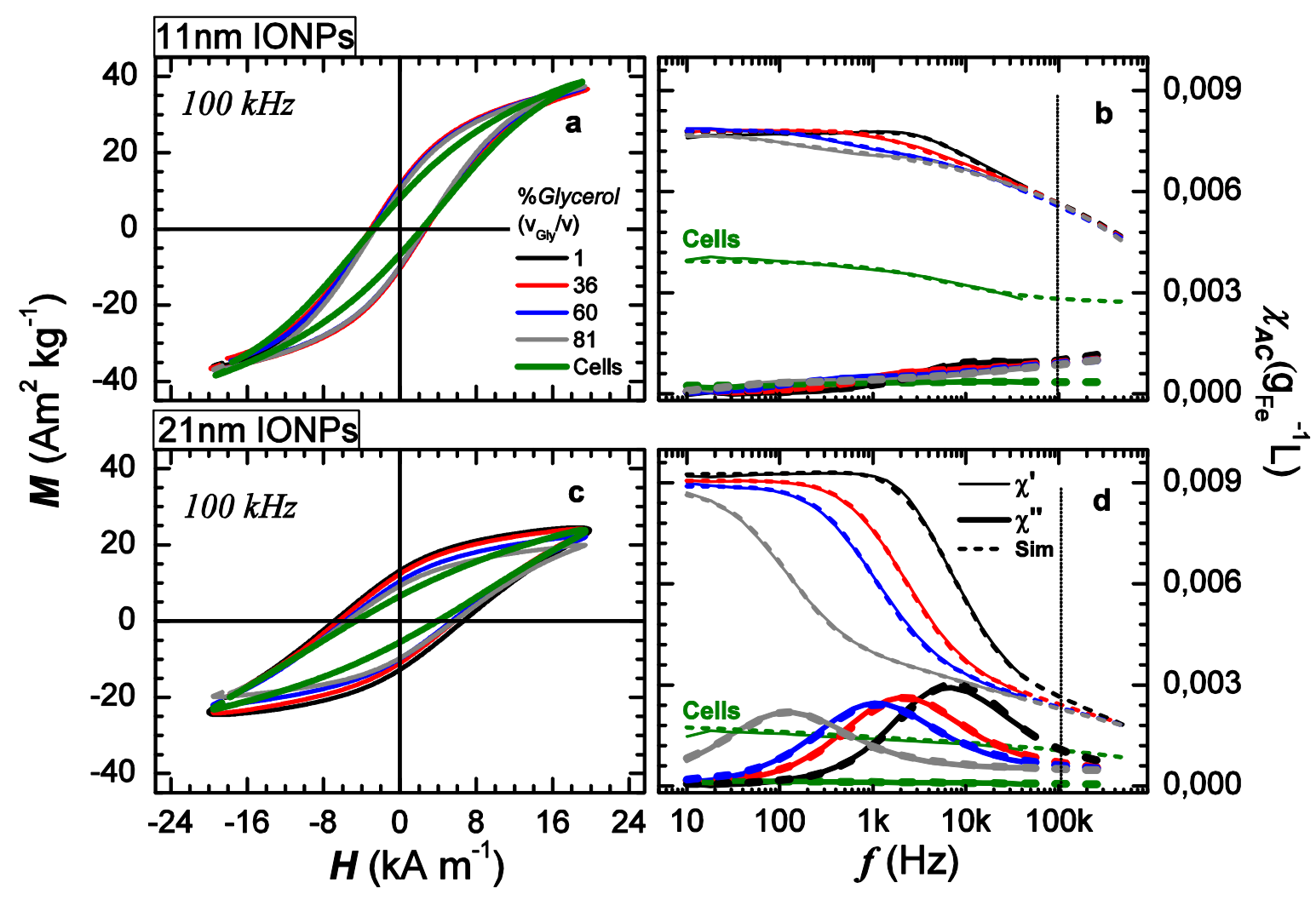

Figure 3. Experimental (solid lines) and simulated (dashed lines) viscosity dependence of AC hysteresis loops under $H_{A C}(100 \mathrm{kHz}$ and $20 \mathrm{kA} / \mathrm{m})$ for a) $11 \mathrm{~nm}$ IONPs, c) $21 \mathrm{~nm}$ IONPs; viscosity dependence of AC susceptometry curves of b) $11 \mathrm{~nm}$ IONPs, d) $21 \mathrm{~nm}$ IONPs. Green lines correspond to magnetic measurements performed inside live cells. The iron content was $1 \mathrm{~g}_{\mathrm{Fe}} / \mathrm{L}$ for all data, except for the $21 \mathrm{~nm}$ IONPs inside live cells $\left(0.7 \mathrm{~g}_{\mathrm{Fe}} / \mathrm{L}\right)$. The vertical dotted lines in b) and d) indicate the $H_{A C}$ frequency employed in AC hysteresis loops measurements. 

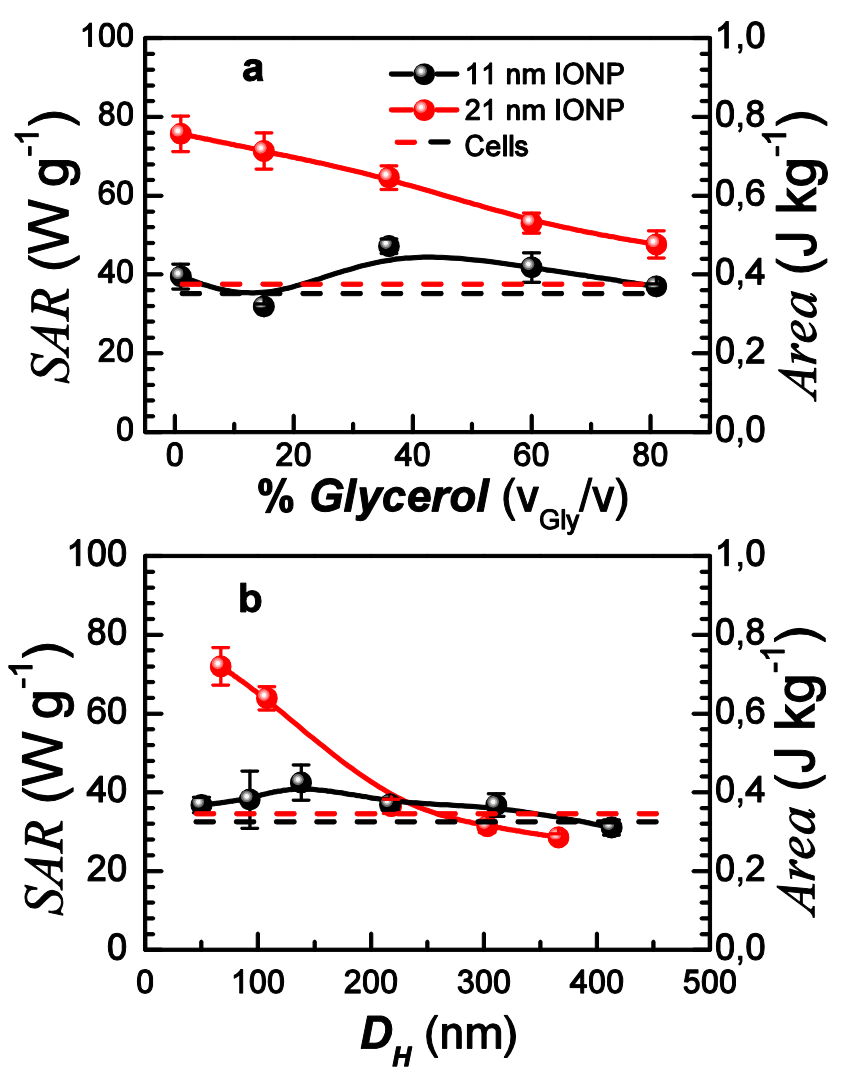

Figure 4. Specific Absorption Rate (SAR) and hysteresis loop area (A) versus a) glycerol fraction $\left.\left(\% \mathrm{v}_{G l y} / \mathrm{v}\right), \mathrm{b}\right)$ IONP hydrodynamic size $\left(D_{H}\right)$. Dashed lines correspond to the SAR values from IONP measurements inside live cells. Data were extracted from Figure 3a,c and 5a,c. 


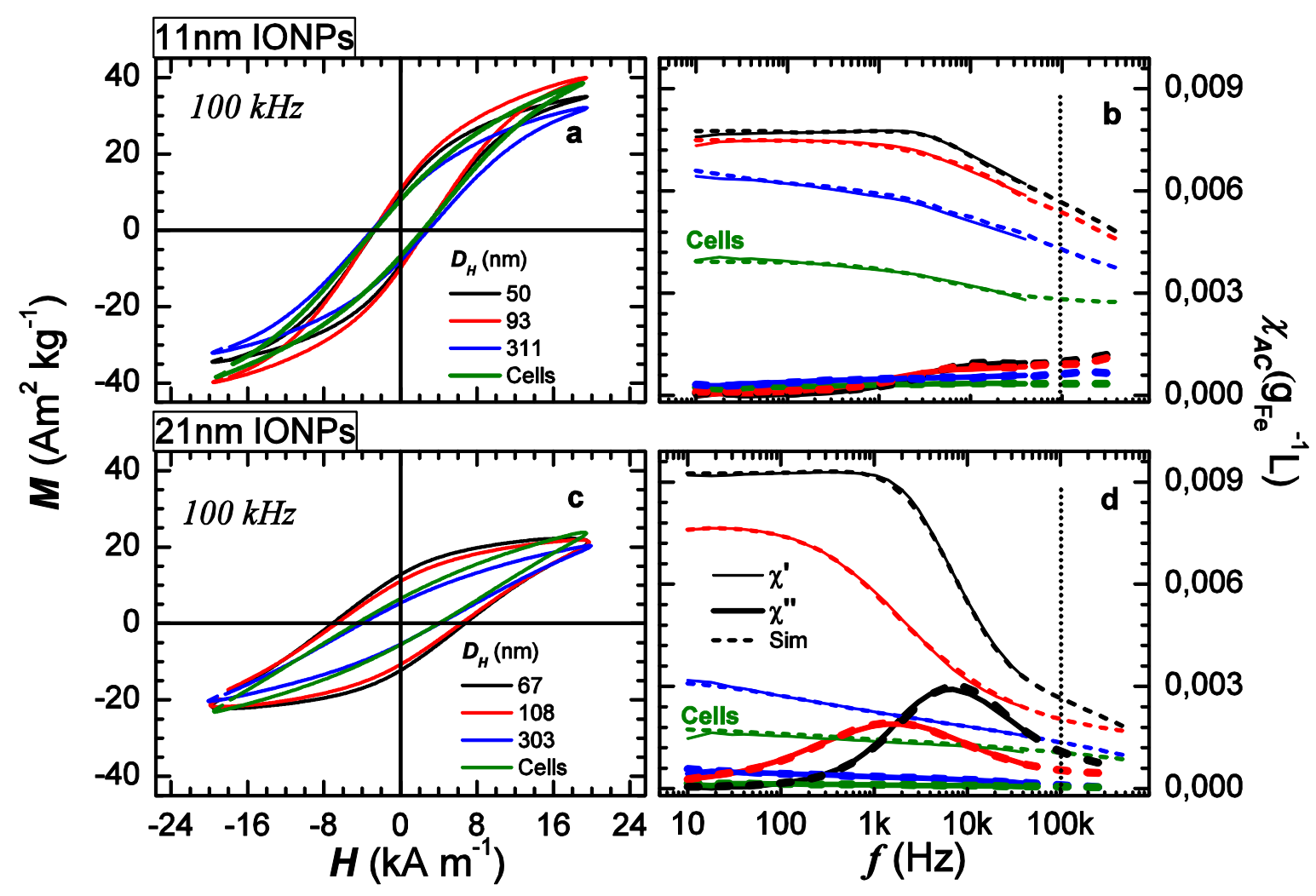

Figure 5. Experimental (solid lines) and simulated (dashed lines) aggregation dependence of AC hysteresis loops under $H_{A C}(100 \mathrm{kHz}$ and $20 \mathrm{kA} / \mathrm{m})$ for a) $11 \mathrm{~nm}$ IONPs, c) $21 \mathrm{~nm}$ IONPs dispersed in $\mathrm{ddH}_{2} \mathrm{O}$ at different hydrodynamic sizes; aggregation dependence of AC susceptometry curves of b) $11 \mathrm{~nm}$ IONPs, d) $21 \mathrm{~nm}$ IONPs dispersed in water at different hydrodynamic sizes. Green lines correspond to the magnetic measurements inside live cells. The iron content was $1 \mathrm{~g}_{\mathrm{Fe}} / \mathrm{L}$ for all data, except for the $21 \mathrm{~nm}$ IONPs inside live cells $\left(0.7 \mathrm{~g}_{\mathrm{Fe}} / \mathrm{L}\right)$. The vertical dotted lines in b) and d) indicate the $H_{A C}$ frequency employed in AC hysteresis loops measurements. 